\title{
A REALIDADE E O PADRÃO NAS ESTADIAS DE ESTUDANTES IRLANDESES DE ERASMUS: "NO ENTENDÍ NADA. AHORA, ESTOY ACOSTUMBRADO A ESTA DESESPERACIÓN DE LA «S»" $"$
}

\author{
LA REALIDAD Y LA NORMA EN LAS ESTANCIAS DE ESTUDIANTES ERASMUS \\ IRLANDESAS: "NO ENTENDÍ NADA. AHORA, ESTOY ACOSTUMBRADO A ESTA \\ DESESPERACIÓN DE LA «S»"
}

THE REALITY AND THE STANDARD IN THE STAYS OF IRISH ERASMUS STUDENTS: "NO ENTENDÍ NADA. AHORA, ESTOY ACOSTUMBRADO A ESTA DESESPERACIÓN DE LA «S»"

\author{
Antonio Daniel FUENTES GONZÁLEZ²
}

RESUMO: São analisados relatos sociolinguísticos de estudantes ERASMUS da Irlanda na Universidade de Almeria (Espanha), mostrando a adequação de uma perspectiva metodológica do múltiplo e do plural a partir de abordagens biográfico-linguísticas. Com isso, pretende-se promover um cenário de ensino mais atento ao plurilinguismo como uma grande plataforma para maior domínio linguístico na ELE e, em geral, em qualquer LE ou L2.

PALAVRAS-CHAVE: Relato sociolinguístico. Programa ERASMUS. Plurilinguismo. Variação sociolinguística. ELE (espanhol como língua estrangeira).

RESUMEN: Se analizan relatos sociolingüísticos de estudiantes ERASMUS de Irlanda en la Universidad de Almería (España), mostrando la idoneidad de una perspectiva metodológica de lo múltiple y plural a partir de planteamientos biográfico-lingüísticos. Con ello, se pretende fomentar un panorama docente más atento al plurilingüismo como gran plataforma para un mayor dominio lingüístico en ELE y, en general, de cualquier LE o L2.

PALABRAS CLAVE: Relato sociolingüístico. Programa ERASMUS. Plurilingüismo. Variación sociolingüística. ELE (español como lengua extranjera).

ABSTRACT: This study analyses some sociolinguistic accounts by Irish ERASMUS students at the University of Almería (Spain). It shows the need and suitability of a more plural and varied methodological perspective based upon biographical and linguistic approaches. This is intended to foster a teaching panorama that grants a higher regard to multilingualism, as it result as a crucial experience for a higher linguistic command in ELE (Spanish as a foreign language) and in general any LE (foreign Language) or L2 [u1] (Second Language).

\footnotetext{
${ }^{1}$ Extrato de uma história sociolingüística de um estudante irlandês de ERASMUS na Universidade de Almeria.

${ }^{2}$ Universidad de Almería (UAL), Almeria - Espanha. Profesor de Lingüística General. Doutor em Filosofia Hispánica pela Universidade de Granada. ORCID: https://orcid.org/0000-0002-6315-3253. E-mail: dfuentes@ual.es
} 
KEYWORDS: Sociolinguistic account. ERASMUS program. Multilingualism. Sociolinguistic variation. Spanish as a foreign language (ELE).

\section{Introdução}

O conhecido programa europeu de intercâmbio acadêmico ERASMUS foi criado em 1987, com desenvolvimento muito rápido, a ponto de hoje fazer parte da imaginação quase obrigatória de muitos estudantes universitários europeus. Não há estudos em excesso relacionados a este programa (fontes GONZ-LEZ, 2020), embora essas lacunas tenham sido superadas em parte ao longo dos anos, tendendo em seus primórdios a estudar mais seus aspectos quantitativos. Sobre o programa ERASMUS, passou a ser enfatizado que "a informação que [...] existe é estatística, em nível institucional [...], ou informativa, focado nos alunos, mas com dados sobre a cidade, campus, etc., algo muito geral e com excesiva informação"3 (BARRAJÓN et al., 2016, p. 1746). Essa informação, que nunca foi conjuntural ou anedótica, considero ser resultado da imagem da Espanha e de suas universidades como destino turístico (vid. para o turismo de idiomas IGLESIAS, 2018), em grande parte baseada na projeção de um patrimônio muito diverso, serviços eficazes e destinos agradáveis, humana e climaticamente. Isso certamente não é ruim, mas, como se verá, pode funcionar em detrimento de prestar menos atenção a muitos aspectos sociolinguísticos e acadêmicos que poderiam pelo menos ser mitigados.

Cabe destacar, em consonância com outros contextos, que este programa implantou plenamente o papel do inglês na UE "come lingua franca nella progettazione europea" (FLORINDI, 2016, s/p), observações que revelarão aspectos importantes neste trabalho. Nesse sentido, observou-se essa preocupação com a distância entre uma Europa de "culturas linguísticas" mais plurilíngues (GARCÍA MARCOS; FUENTES GONZÁLEZ, 1997) e outra que, de fato, tende ao anglo-monolinguismo como uma forma ideológica de multilinguismo monolíngue (MEURER, 2019). Enquanto isso, esse crescente anglo-mononolinguismo parece ser cancelado em muitas situações de negócios, de trabalho (ALARCÓN, 2005) ou acadêmicas (MARTÍN ROJO; RODRÍGUEZ, 2016, p. 125-127), em que as línguas são capital linguístico e sua diversidade é celebrada.

Dentro das qualificações linguístico-filológicas, a situação apresenta suas particularidades. Neste trabalho vou focar especialmente na análise do papel, às vezes

3"la información que [...] existe es, o bien estadística, a nivel institucional [...], o bien divulgativa, enfocada al alumnado, pero con datos sobre la ciudad, el campus, etc., algo muy general y con excesiva información”. 
contraditório, que as estadias ERASMUS desempenha no campo da ELE. A partir das especificidades encontradas, proponho-me a fazer analisando relatos sociolinguísticos escritos voluntariamente por estudantes da Irlanda da Universidade de Almeria (UAL) que apontam os acontecimentos mais importantes, tanto endo- quanto exolinguísticos. Ou seja, com as narrativas alternativas que esses registros sociolinguísticos podem apresentar, poderíamos criar oportunidades de ensino, pois somos muito determinados pelo desempenho burocráticoadministrativo e não tanto pelo aspecto pessoal da educação (BRUNER, 1999 [1997], p. 5258): podemos parar de pensar em cifras para ler a escrita e a vida dos próprios alunos.

De um modo geral, essa nova vida linguística estudantil deve ser desenvolvida em um ambiente urbano, cujo espanhol (andaluz oriental) é basicamente caracterizado, em seu nível fónico ${ }^{4}$ por: 1) A perda do /-s/, tão característico de todo o domínio linguístico iberopeninsular sulista, em Almería é parcialmente atenuada na máxima tensão comunicativa, ou seja, que há uma tendência de repor o /-s/ nos estilos mais formais, mesmo em situações de tensão média; 2) As outras consoantes implosivas mantêm essa atenuação, mas diminuindo seus percentuais e com maior inclinação para aspiração em detrimento da abertura e alongamento das vogais anteriores; 3) A distinção é a variante prioritária da oposição /s/-/Ө/ explosivas, seguido por ceceo localizado nos estratos e bairros socioculturais baixos; não se encontra sesseo, nem a variante aspirada que é, contudo, registrada em outras áreas da província; 4) Os mesmos condicionamentos sociolinguísticos do ceceo se reproduzem em termos de fricatização de /ĉ/; 5) Os rotacismos de /r/-/l/,, implosivos e agrupados na tensão de sílaba são exclusivos das classes socioeconômicas baixas e carecem de mudanças de acordo com a tensão comunicativa, embora a queda de /-r/ nos infinitivos, especialmente seguida pelo pronome pessoal átono, seja muito estabelecida em todo o espectro sociolinguístico; 6) Em relação ao /-d-/ dos particípios, sua perda, tão difundida no mundo de língua espanhola, mas com restrições aos usos formais; e 7) Alguns fenômenos fonéticos tradicionalmente ligados aos estratos inferiores, como as trocas vocálicas /i, o/>/e, u/, altamente estigmatizadas, não têm presença nos espanhóis da cidade (GARCÍA MARCOS, 1993, p. 562-564).

\section{O papel das estadias no desenvolvimento da idioma em L2 ou LE}

Tanto nos circuitos bibliográficos acadêmicos quanto no discurso hegemônico comum sobre a aprendizagem de línguas, costuma-se considerar que qualquer estadia no país cuja língua é estudada é muito positiva, e isso desde vários pontos de vista: linguístico-aquisitiva,

${ }^{4} \mathrm{Que}$, como você verá, é muitas vezes notado por sua dificuldade em entender. 
intercultural, política, econômica, de desenvolvimento pessoal, etc. Contudo, uma observação detalhada das estadias colocou sobre a mesa aspectos tão inesperados quanto indesejados. Assim, Santiago Guervós e Fernández González (2017, p. 74-80) descrevem o impulso da indústria das estadias lingüística que, em qualquer um dos casos, deve forçar os professores a pensar contextualmente e desdogmatizar atitudes.

Se nos parofundamos em alguns aspectos, sabe-se, por exemplo, que estudantes universitários britânicos muitas vezes reforçam suas percepções estereotipadas ou que as estadias para fins de trabalho geram julgamentos mais favoráveis sobre o país de chegada do que as estadias acadêmicas (COLEMAN, 2001, p. 65). Em outro sentido, para fins profissionais, Pérez Vidal (2007, p. 25) não tem dúvida de que as estadias no exterior são positivas e necessárias, uma vez que

[1]'estudi sistemàtic dels efectes i beneficis de les ES ens permet comprendre com ens comportem en circumstàncies de canvi de context cultural i lingüístic. Els elements que configuren les estades a l'estranger interactuen amb el nivell de llengua a l'inici de l'ES, amb les característiques de personalitat i amb la capacitat de relacionar-se i d'establir contactes amb parlants de la llengua dels aprenents. Finalment, l'ES permet obtenir la pràctica lingüística necessària per fixar formes gramaticals. Aquesta cadena de factors interrelacionats afectarà de manera decisiva l'èxit de l'ES, en contrast amb un context d'aprenentatge a l'aula al país d'origen durant el mateix període de temps.

Séré (2006, p. 108), por sua vez, destacou do programa ERASMUS seu caráter eminentemente positivo, com suas contradições a partir de um quadro de ação pouco definido, mais potencializador do "aprendizado da língua do que da inserção na sociedade", com modelos interativos em que há uma "massa dos nativos que no tentam ou não conseguem penetrar"

Também foi enfatizado que há um grande contraste nos estudos sobre o efeito do input sobre a pronúncia, de tal forma que "a quantidade de input no contexto natural tem sido, na maioria dos casos, o tempo de permanência em um país onde a língua-alvo é falada"6 (RECAJ, 2008, p. 30), cálculo que, desde já, vem do esforço em padronizar e correlacionar o tempo da estadia com as 'repercussões lógicas' na aquisição de LE ou L2. Em ambos os casos, esse "contexto natural" é geralmente muito mais rico do que o indicado por essas percepções anteriores. No entanto, as imagens da indústria linguística desenvolveram muito este tema, a

\footnotetext{
5“masa de los nativos en la que no intentan o no pueden penetrar".

"6" la cantidad de input en el contexto natural ha sido en la mayoría de los casos la duración de la estancia en un país donde se habla la lengua meta”.
} 
ponto de a metáfora da "imersão" no contexto natural migrou também para ambientes mais artificiais e didáticos (FUENTES GONZÁLEZ, 2015).

Pinar (2015, p. 13-51) e Lindqvist (2017, p. 28-30) anlisam o papel das estadias através de uma série de fatores, o que novamente enfatiza a disparidade de resultados. Por outro lado o estudo de Barrajón et al., (2016, p. 1746), dedicado a estudantes de disciplinas lingüístico-filológicas hispânicas, é particularmente interessante para o trabalho que surge aqui, pois descobre aspectos muito comuns, como a dificuldade em tentar enunciar claramente uma série de rotinas acadêmicas genuínas de nossa tradição e cultura universitárias, certamente muito variáveis e cheias de incertezas, como as relações entre professores e alunos ou os modos e critérios de avaliação , bem como práticas muito interessantes, como as do voluntariado linguístico (también en BOLADERAS TACHÉ, 2005).

Pozo-Vicente e Aguaded-Gómez (2012, p. 441), sem deixar de destacar ao mesmo tempo a divergência nos resultados, enfatizam a capacidade do programa ERASMUS em motivar a aquisição de competências interculturais, uma vez que "não só incentiva o aprendizado da língua estrangeira, mas também promove [...] entendimento e coesão entre membros pertencentes a diferentes culturas, conscientizando a cidadania europeia entre a população estudantil"”7.

Em diferente trabalhos ${ }^{8}$, Meunier $(2010 ; 2011 ; 2013 ; 2018)$ salienta que a consciência y as atitudes sociolinguísticas -influenciadas por quadros prediscursivos, a veces autênticss 'ideias tóxicas'- costumam operar categorizando e essencializando os idiomas, seus discursos, seus sotaques e classificando seus falantes, también mediante modelos de correção linguística que se nutrem da exemplaridade do falante nativo (quase falante-ouvinte ideal). Em qualquer caso, já se verá posteriormente com mais detalhes, o campo do trabalho sociolinguístico, não apenas percepção ou avaliação quantitativa, sociolinguística (crenças, consciência e atitudes) será de grande proveito neste trabalho (FUENTES GONZÁLEZ, 1996; 1996a; GARCÍA MARCOS, 1999; GARCÍA MARCOS; FUENTES GONZÁLEZ, 1997; GARCÍA MARCOS; MANJÓN-CABEZA CRUZ, 1989; MANJÓN-CABEZA CRUZ, 2018).

Assim, ao chegar ao destino linguístico, a experiência do aluno fica frequentemente paralisada quando ouve falantes que não utilizam as formas prescritas pela gramática normativa, fortemente destinadas ao ideal do padrão didático, mesmo que esses alunos de

7“"no solo fomenta el aprendizaje de la lengua extranjera, sino que además promueve [...] el entendimiento y la cohesión entre miembros pertenecientes a diferentes culturas, lo que da conciencia de ciudadanía europea entre la población estudiantil".

${ }^{8}$ Por razões de espaço, não são discutidos estudos mais específicos aqui que visam atender às necessidades na chegada dos alunos do ERASMUS. Em todo caso, vide, como mostra de exemplo, Vázquez (2006). 
ERASMUS usem convenções pragmático-discursivas dos novos com quem se encontrou: estão mais influenciados por suas tradições didáticas fortemente nômicas do que pelas práticas linguísticas mais comuns na comunidade de chegada. Devem se transformar em mutantes linguísticos, com tensões identitárias, imobilizados por sua aprendizagem anterior mas impelidos a se moverem diante dos novos entornos. Às vezes flutuam com grande angústia através de diferentes regras e posições, o que poderia aliviar - originalmente - uma abordagem dialética do "discurso epilinguístico".

Diante desse panorama, a nova 'geração erasmus' deve ser responsável e consciente de seu papel na construção de uma Europa mais cívica, promovendo atitudes mais tolerantes em relação à linguodiversidade. Uma visão multilíngue seria mais maleável do que modelos tirânicos de proficiência linguística. Por enquanto, esses princípios prescritivos, como veremos, são contestados pelo conjunto de características de verdadeira competição multilíngue (GONZÁLEZ PIÑEIRO; GUILLÉN DÍAZ; VEZ, 2010), como pode ser a natureza parcial e imperfeita das habilidades, ou o princípio do desequilíbrio comum dessas habilidades, às quais, por sinal, não são alheios aos falantes nativos considerados cultos.

Outro importante bloco de trabalhos de referência neste estudo é o conjunto dedicado às variedades andaluzas de espanhol, especialmente no que diz respeito às obras dedicadas ao /-s/ (LAMÍQUIZ IBÁÑEZ, 1976; SALVADOR, 1977; LÓPEZ MORALES, 1984; GARCÍA MARCOS, 1987; MÉNDEZ GARCÍA DE PAREDES, 2008; MOYA CORRAL, 2011), que, como se sabe, não é exclusivo do Sul da Espanha, pois também é encontrado em outras áreas do ambiente de língua espanhola (LÓPEZ SERENA, 2011).

\section{Análise de relatos sociolinguísticos: estudantes Erasmus irlandesas na UAL}

\section{Aspectos metodológicos}

Muitas vezes é proposta uma abordagem metodológica múltipla, quando se analisa situações de contato (linguísticas e culturais). Galindo y Díez (2016, p. 2182), tanto para questionários quanto para outros procedimentos, ponderam que a coleta de dados não é tão fácil, o que resulta na necessidade de coletar qualitativamente experiências durante uma estadia do aluno, expandindo-as por meio de entrevistas com professores, funcionários administrativos do programa e famílias anfitriãs. Pozo-Vicente y Aguaded-Gómez (2012, p. 441) partem de um amplo modelo, baseado em uma metodología quanti- e qualitativa. Os instrumentos aplicados são o questionário-entrevista e o fórum de discussão. Séré (2006) e González-Monteagudo (2015, p. 262-264), a partir de sa perspectiva, enfatizam o grande o 
potencial das entrevistas biográficas, ferramentas essenciais para analisar mecanismos de aprendizagem individual e coletiva de uma língua e seu universo cultural, ou como as ideias de aprendizagem desenvolvem e transformam identidade, projeto de vida e capital cultural.

Lima (2014, p. 47) defende uma perspectiva sócio-interacionista para melhor delinear os aspectos teóricos e metodológicos da interculturalidade e da intersubjetividade no ensino de línguas. Assim, não se deve ignorar que o professor é um interlocutor privilegiado por conta da comunicação estabelecida com seus alunos: com novidades, motivadora e significativa também para ele, de modo que o ensino de línguas constitui um processo interpessoal e intercultural permanente na sala de aula e também na vida (LIMA, 2014, p. 5556). Com tudo isso, a pesquisa através de autobiografias linguísticas está se mostrando promissora, pois ativa aspectos da observação muitas vezes despercebidos ou invisibilizados (CARMONA YANES, 2018; WEXELL-MACHADO; ALCARAZ; BENÍTEZ, 2019).

No caso específico deste trabalho, essa interlocução de ensino é assumida primeiro com a ideia de melhor acesso ao quadro sociolinguístico pessoal que os alunos Erasmus apresentam durante suas estadias. Trata-se de um trabalho que pode ser considerado exploratório, uma vez que só podemos esperar uma série de pistas orientativas que, na continuidade desses estudos, pode-se levar a uma visão geral mais completa e abrangente. Também é importante salitenar que este estudo é moldado por minha observação participativa e contínua - do desenvolvimento do programa ERASMUS no UAL desde 1993, o qual reiterou alguns aspectos. Por exemplo, a sensação, compartilhada, de que entre os estudantes há uma forte distância entre autóctone' e 'internacional' (reiterando o acima por SÉRÉ, p. 108). Além disso, o nível de proficiência estritamente linguístico do espanhol fica melindrado por certos fatores pragmalinguísticos, como volume de voz, familiaridade excessiva e "desordem" interativa (de acordo com estudantes estrangeiros), bem como por uma atitude muito negativa dos estudantes erasmus em relação à escuta espanhola em Almeria.

Diante de tudo isso, darei um exemplo, como um caso que em muitas discussões de classe se costuma apresentar: uma aluna está em seu apartamento. O interfone toca. Ela pergunta “¿Sí?” ou “¿Quién es?”. Resposta: “Abre!”. Estudantes estrangeiros muitas vezes apontam isso como imperativo agressivo (¡Abre!); todavia, o alunado de Almeria não o considera de nenhuma maneira assim, mas como uma intervenção eficaz. Essa visão diferente significa que diferentes modelos culturais atuam, neste caso, de cortesia (BORREGO NIETO et al., 2016, p. 367-380), que entendo ser uma excelente desculpa para desvendar o 
etnocentrismo (linguocentrismo, de agora em diante) com o qual cada pessoa muitas vezes valoriza os fatores de comunicação.

Com todo esse contexto, pensei em ouvir e ler a própria voz dos alunos, através de entrevistas sociolinguísticas, grupos de discussão, ou as chamadas biografias linguísticas, histórias orais ou revistas etnográficas, pois interpretar, gravar e aprender a ouvir e ler histórias é empatia com aqueles que as produzem. Contudo, essa riqueza metodológica foi, em última análise, muito ineficiente, pois foi um impulso para obter um número abundante de histórias, porém poucas entrevistas sociolinguísticas ou sessões gravadas de grupos de discussão.

Daí este trabalho discute um corpus de cinco histórias escritas pelos próprios alunos (dos cursos 2016-2017 a 2019-2020). Tais histórias foram escritas voluntariamente. Como a inibição nessas tarefas cooperativas é comum nesses casos, foi previsto um conjunto de orientações para que - na medida do possível - fossem eliminados possíveis horror vacui. Em suma, essas orientações nos convidaram a escrever experiências relacionadas à sua estadia: extensão livre ${ }^{9}$, escritas com estilo pessoal, que refletissem as situações linguísticoexperienciais mais importantes em sua estadia, sem necessariamente aderir a um plano linguístico específico; solicitando uma descrição, também, de aspectos para- e não-verbais; experiências concretas sobre tipos de linguagem; também sobre situações cooperativas que pudessem ter sido encontradas ou não por povos indígenas; sobre suas mudanças de opinião em relação às expectativas iniciais e à realidade encontrada e se essa visão anterior foi mantida ou fortalecida; igualmente, sobre as linguagens utilizadas na interação cotidiana; quais recursos usavam para entender e fazer-se entender; e, finalmente, em uma breve autoavaliação dos aspectos linguísticos da (auto-) melhoria ou uma avaliação geral da estadia.

Assim, cinco dos seis estudantes da Irlanda durante o período indicado ${ }^{10}$ entregaram seu relato, que por sua vez, procedeu de um corpus de 43 relatos, se acrescentamos os de estudantes de outros países (conforme mencionado, da União Europeia e da China). Precisamente, decidi destacar a análise nos relatos obtidos dos estudantes irlandeses devido às especificidades apresentadas, às quais deve-se acrescentar que a própria universidade receptora (a de Almería, Espanha) não requer um nível específico de proficiência em espanhol, mesmo que se pressuponha um dado nível para empenhar-se em estudos de

${ }^{9}$ Nenhum relato excedeu 1200 palavras.

${ }^{10}$ Todas as estudantes cursaram disciplinas do primeiro quadrimestre (de setembro a fevereiro). 
Filologia Hispánica ${ }^{11}$. De fato, a partir de minha própria experiência docente com essas estudantes $^{12}$ posso salientar que seu nível de proficiência era insuficiente, às vezes notoriamente insuficiente, o que começou a chamar a atenção também para o restante dos alunos, que muitas vezes explicavam essas deficiências pela autossuficiência produzida pela língua inglesa como L1, uma língua internacional por excelência.

Como dito acima, dentre o corpus até o momento compilado compilado, detenho-me, por suas particularidades, em cinco relatos de estudantes da Irlanda, pois fomentam experiências e reflexões significativas diferenciadas do restante (basicamente estudantes da União Europeia e da China), especialmente porque as estudantes irlandesas são mais propensas para a realização vivencial, e não tanto linguística sensu stricto. Ou seja, sentem um grande sentimento de sucesso como mulheres que estão começando a ser independentes e a gerenciar sua autonomia geral de modo pleno, aspecto nem sempre presente em outros relatos de estudantes de diferentes nacionalidades e que, quando se faz presente, não é percebido de forma tão intensa.

Com circunstâncias em parte próprias, essas estudantes irlandesas se adaptaram a seu novo contexto de vida trabalhando como professoras de inglês ou de au pair $^{13}$ e viajando muito, o que lhes serve para explorar varios sotaques do espanhol. Especialmente nos primeiros momentos um grande apoio foi o gestual, que Patricia ${ }^{14}$ aprecia muito, porque

[d]evido ${ }^{15}$ meu nível básico de espanhol, no início, aprendi a importância da linguagem corporal para entender uma mensagem; porque eu acho que aprender uma língua é um dos elementos mais importantes e é muito útil. Quando eu não entendo uma pessoa que fala demasiadamente muito rápido, através da linguagem corporal podia entender quase tudo.

Margaret também valoriza a ênfase gestual "para explicar as coisas", embora ela tenha tido o azar de descobrir que "algumas pessoas simplesmente repetiam da mesma maneira. Eles não falavam mais devagar ou explicavam de outra forma, o que às vezes dificultava a comunicação com eles", explicando que "a maioria dos espanhóis em Almeria são tolerantes

\footnotetext{
${ }^{11}$ É conveniente notar que esta política acadêmica "de manga ancha" está sendo questionada pelos professores, a ponto de alguns convênios terem sido cancelados, devido à falta de proficiência mínima em espanhol de alguns estudantes de intercâmbio internacional.

${ }^{12} \mathrm{Um}$ trabalho futuro poderia indagar todos esses aspectos com a variável de estudantes da Irlanda em outros tipos de estudos, uma vez que em muitos deles o ensino é realizado na língua inglesa, como medida do Plano de Fomento do Plurilinguismo da Universidade de Almeria.

${ }^{13}$ Ao contrário de grande parte dos estudantes poloneses, que trabalhavam cuidando de crianças, tarefa essa que para eles era uma excelente oportunidade para aumentar o conhecimento da língua e cultura espanhola; Em vez disso, as estudantes irlandesas cuidavam de crianças para elas aprenderem inglês (FUENTES GONZÁLEZ, 2020).

${ }^{14}$ Oculto o local das estudantes, alterando seus nomes.

${ }^{15}$ Exceto por algum esclarecimento, mantenho a escrita original das histórias.
} 
com os estudantes erasmu, talvez porque Zapillo [bairro populoso da cidade, à beira-mar] em Almería tem muitos estudantes erasmus nesta região". Esta série de inconvenientes é às vezes resolvido com certa endogamia linguística, como muitos passaram "a maior parte do tempo [...] falando inglês a irlandeses e amigos britânicos", zona de conforto que, entendo eu, se amplía pela demanda geral por experiências em língua inglesa, pois é a língua internacional por antonomásia (vide., igualmente, MITCHELL; McMANUS; TRACY-VENTURA, 2015). De qualquer forma, este uso do inglês como refúgio tem fortes nuances de identidade, como sentem-se julgadas quando falam espanhol. O desconforto, além disso, chegou a fazê-las se sentir estúpidas para esclarecer mal-entendidos com os espanhóis "Vão falar tão rápido quanto da primeira vez. Não tentam diminuir a velocidade para facilitar as coisas.”.

Pela significância no conteúdo, vou me ater a seguir a) no "encontrão" da chegada; b) na atividade acadêmica; e c) na 'ausência' de /-s/, temas que, como você verá, estão interrelacionados.

\section{A experiencia em Almeria: a chegada como encontrão}

Para as cinco alunas, a experiência provou ser um rito de passagem, ancorado no reconhecimento explícito de que chegaram com baixo nível de espanhol. Patricia sentiu que tinha sido

um ano memorável da minha vida e eu acho que o programa Erasmus é um dos melhores programas culturais que existem, pois oferece uma grande variedade de atividades e há uma mistura de culturas e diversidade de todo o mundo... que foi a primeira vez que morei sozinha e fora da minha casa, $e$ aprendi muitas coisas, aprendi a lavar roupas, pratos [...] Era uma oportunidade essencial para ver outra cultura e as diferenças e semelhanças entre as nossas, às vezes tinha umas coisinhas, mas não era um problema.

Maria também enfatiza a superação dos problemas iniciais, após uma primeira separação de seu ambiente e entes queridos:

Lembro que quando fui ao aeroporto chorei tanto, não tinha absolutamente ideia nenhuma quanto de um incrível ano meu Erasmus chegar a ser [...] Primeiro fui para Almeria, tive vários problemas. [...] Foi a primeira vez na minha vida que tive que consertar as coisas por mim mesmo. Não tenho minha mãe e meu pai comigo para me salvar. No começo foi muito difícil, especialmente porque eu tinha que comunicar esses problemas através de uma linguagem diferente. Mas eu sou grata por esses tempos dificeis, porque eles me fizeram crescer em uma jovem independente e responsável.

O relato de Deirdre apresenta um desejo contínuo de viajar. Não se lembra dos problemas do início; em vez disso, destaca a apreciação de contrastes contínuos e positivos, 
de Madri com Almería, e de ambas as cidades com a India ${ }^{16}$, enfatizando a gastronomia e museus como antonomasias culturais.

Margaret tende a dar mais importância para o aprendizado de idiomas, como ela decidiu ficar

um ano todo, porque meu nível de español não é muito bom, e pensei que estudiar um ano no exterior poderia me ajudar a melhorar meu padrão de idioma. Quando cheguei pela primeira vez a Almería, meu anfitrião me buscou no aeroporto. Ele só falava espanhol e pouco inglês. Como eu não tinha revisado nenhum espanhol, desde minhas provas em maio de 2017, eu sabia que já estava ficando para trás. Achei escutar e entender o idioma difícil a principio.

Anne, por sua vez, sofre um tremendo choque linguístico, no sentido de que, desde o início, sua

experiência até agora aqui não era o que eu esperava. Para começar, o idioma aqui é muito difícil de entender. Aprendi antes de vir para Almeria que as pessoas aqui não falam o espanhol que aprendi na minha universidade. No entanto, eu não esperava que fosse tão diferente como o encontrei quando cheguei aqui. Não sei se isso ofenderá alguém que mora em Almería, mas sempre me disseram que o melhor e mais bonito espanhol que você ouve é em Madri. A língua em Almeria é difícil de entender e é dificil se adaptar a ela quando meus professores em casa falavam espanhol básico muito bem para nós em sala de aula.

Como se pode ver, as estudantes irlandesas, em maior ou menor grau, chegam a negociar e reconfigurar suas identidades como aprendizes durante sua estadia em Almeria, gerenciando efetivamente encontros interculturais, que Galluci (2011) observou entre erasmus britânicas durante um ano de estadia na Itália. Da mesma forma, essas estudantes, em geral parecem apresentar como consequência uma estrutura atitudinal identificada -também- em estudantes futuros professores espanhóis da vizinha Universidade de Granada, quando projetam uma visão ambivalente do andaluz: muito positiva sobre seus usos sociais gerais e suas paisagens, mas internalizando a estigmatização de "muitos traços linguísticos andaluzes, que levam a associar o andaluz a um nível sociocultural baixo ou a menosprezá-lo à categoria de jargão" (MANJÓN-CABEZA CRUZ, 2018: p. 175)".

${ }^{16}$ Comparação que a estudante faz por causa de suas viagens para aquele país. 


\section{A atividade acadêmica}

Todos as estudantes irlandesas orientam seus relatos para a superação de dificuldades; destacam os problemas de sua atividade universitária: a volumosa papelada, a incompreensão dos conteúdos, a duração excessiva das aulas, também o inglês de Almeria (a seu ver, péssimo), mas -igualmente- a imensa aprendizagem lingüística e literaria e o clima benigno e brilhante. A compreensão está no interdito do início, especialmente porque, tanto as irlandesas quanto outras estudantes, apontam para a diferença entre o espanhol anteriormente aprendido e o que encontram em Almeria, um verdadeiro desencontro. Patrícia escreve que

no começo [...] não entendia nada, estaba perdida e todos os alunos espanhóis falavam muito rápido para o español que eu tinha aprendido. Fui para aula um tanto desconcertada e confusa já que não tinha muito a ver com o que eu tinha aprendido. Mais tarde, no segundo quadrimestre um colega de turma, amigo meu, me explicou a dificuldade para aprender español aquí, era o sotaque andaluz[...] mas à medida que passa o tempo as coisas foram mudando, comexei a fazer trabalhos e aprendi muito vocabulario e frases novas. Na Irlanda, aprendemos a língua espanhola através do inglês ou «spanglish» não faz sentido, mas era mais fácil. Não há melhor frase que explique a experiência de aprender outra língua do que "aprender a sobreviver".

Mary também se sentiu "perdida em toda aula" quando começou o curso, abatida pela dureza do aprendizado. Determinada a consertá-lo, ela fez aulas particulares de espanhol e melhorou significativamente, mais em compreensão do que em produção, dado que o segundo semestre foi "muito mais fácil porque, embora eu não seja fluente, eu posso entender um monte de coisas e me sinto muito mais à vontade com o idioma".

Margaret sentiu grande insegurança, provavelmente apoiada por opiniões anteriores, como a velocidade dos espanhóis falando, atribuída ainda mais ao meio entorno andaluz ${ }^{17}$, mas, em grande parte, foi capaz de seguir as aulas, mesmo não entendendo algumas palavras: "Eu era capaz de juntar algumas das palavras e descobrir o que estavam tentando dizer. Quanto mais eu ia para a faculdade, mais ficava um pouco melhor e me acostumei com o Almería-Espanhol [o espanhol de Almeria]". É muito interessante apreciar como esta aluna distingue o que com certeza ocurre também em seu país, as diferenças linguísticas situacionais:

\footnotetext{
${ }^{17}$ Lamíquiz Ibáñez (1976) já destacou - na análise de um estudo contrastante da oralidade das pessoas educadas de Madri e Sevilha, que, embora em 30 minutos de gravação, os entrevistados de Sevilha proferiam 500 termos a mais do que os entrevistados em Madri, os Sevillians, entre esses termos, emitiram uma média de 250 palavras, em comparação com 400 dos madrilenhos. Ou seja, o povo andaluz repetiu muito mais algumas palavras e expressões, alimentando um discurso mais fluido.
} 
Também notei que a língua falada na Universidade é diferente da língua que ouço de pessoas sentadas em cafés, restaurantes ou mesmo em lojas. Por exemplo, acho que a lingua falada na Universidade é mais formal em sua abordagem. [...] Na minha opinião, acho que a linguagem usada por pessoas em lojas ou restaurantes é mais expressiva, de certa forma. Sua linguagem corporal é relaxada, a velocidade de sua fala é estável, o que torna mais fácil para mim entender e a linguagem em si parece mais informal.

Anne, por sua vez, tende a escrever sobre questões de identidade, o sentimento de ridicularização quando se sente mal compreendida ao falar espanhol, ou quando tenta entendê-lo. Tanto que no início lamenta o baixo nível de inglês no ambiente almeriano, também do corpo docente universitário, para encontrar, então, as vantagens de se sentir compelida a falar espanhol.

Deirdre, novamente, evoca a ideia de que "Os espanhóis são conhecidos por falar rápido. Mas lembra, na frente de um professor que "falou muito rapidamente e eu achei extremamente difícil entender o que foi dito":

por outro lado, tinha outros professores que falavam em um ritmo normal e constante. Eu era capaz de acompanhar o que eles estavam dizendo. Em certas situações, aprendi que estava usando palavras incorretamente, seja por pronúncia ou porque estava usando palavras diferentes para as situações erradas.

Ideias anteriores, às vezes muito preconceituosas, também determinaram em Patrícia

que

[u]ma das diferenças mais fundamentais foi a pronúncia aquí. Visit[ei] $]^{18}$ outros lugares na Espanha durante a minha estadia e era óbvio que as pessoas na Andaluzia e Almeria falam um pouco diferente. Aqui, o ritmo era mais rápido e mais variado, e os sons eram variados. Na minha universidade, conheci uma garota que estudou na UAL no ano passado e me disse para me preparar porque é muito difícil entender e estar familiarizado com o estilo de vida das pessoas aqui em Almeria. [...] Além disso, a irlandesa do ano passado disse que perdeu tantos temas, porque a faculdade era tão difícil. Isso estava me fazendo falhar antes de chegar a Almeria.

\section{A 'ausência' de /-s/}

Com ênfase muito maior do que outros estudantes de mobilidade internacional (vide. FUENTES GONZ-LEZ, 2020), as estudantes irlandesas se opuseram totalmente à não pronúncia de /-s/, que pode ser enquadrada em um quadro mais geral do ensino da variação na ELE (GEESLIN; GUDMESTAD, 2008; SALGADO-ROBLES, 2011; GEESLIN, 2011;

\footnotetext{
${ }^{18}$ Por parte do autor, o texto em parênteses quadrados também é usado para manter a legibilidade dos textos.
} 
RINGER-HILFINGER, 2012). Do conceito de língua como norma, elas vêm de um sistema de aprendizagem, como tantos, governado por um prescritivismo e uma lacuna dicotômica que exclui o que não está incluído no conjunto nômico. É por isso que Margaret argumenta que

[en] minha universidade de origem, eu me acostumei com castelhano, então começar a Universidade em Almería e me acostumar com o espanhol andaluz me confundiu muito. Eu acho muito difícil entender as coisas, e eu ainda me pergunto se eu ouvi a coisa certa que uma pessoa espanhola está dizendo[...] A surpresa linguística mais surpreendente que encontrei é em certas situações, quando um espanhol está falando, e eles podem não pronunciar 's', pois eu ainda fico confuso quando eles estão falando. Eu sempre me pergunto se eles estão dizendo palavras e apenas não pronunciando o 's', ou se nunca tinha escutado essas palavras em espanhol.

Da mesma forma, Deirdre observa que

muitas pessoas, que estavam falando em espanhol, não pronunciavam a letra 's' em algumas palavras [...] Foi confuso no início porque eu comecei a me perguntar, se eles estavam falando palavras e não pronunciando a letra 's' sobre elas, ou se eles usavam palavras diferentes que eu ainda não tinha aprendido.

Patricia resume sua percepção acústica dizendo que

na maioria das vezes o " $s$ " final de uma palavra não existe, este "s" era absolutamente minoritário na comunidade. A pronúncia em Almería é única e especial. [Quando] eu cheguei, um homem me perguntou em um restaurante simplesmente "[¿T]e gusta el pescado?» e não entendi nada. Agora estou acostumada a essa 'desesperación ${ }^{\prime 19}$ do «s».

Tudo isso, Anne associa-lo com falta de vontade: "Aqui em Almeria, eles não gostam de pronunciar os "s" em palavras. E eu me pego aprendendo o espanhol errado. Estou começando a dize 'gracia' e 'bueno d[í]a' no lugar de 'Buenos d[í]as'. Isso não é bom para meu espanhola [Isto não é bom para meu espanhol]”"

Não é por acaso que esas avaliações sejam implantadas. Na melhor das hipóteses, duas posições podem ser observadas para o fenômeno das marras. Por um lado, SALVADOR (1977) atribuiu ao enfraquecimento consonantal em posição implosiva um papel que afetou a abertura, não só das vogais finais, mas das de toda a palavra, dobrando-as fonologicamente em abertas e fechadas; e, por outro lado, o de LÓPEZ MORALES (1984), reexaminar a questão sem drama, apontando que é o contexto oracional e amplamente comunicativo que

${ }^{19}$ Trata-se, isso sim, de um erro interessante, porque se quis dizer 'desaparición'. 
determina o número (plural ou singular), por exemplo, e não a mera presença-ausência da marca de /-s/.

Em ambos os casos, chama muito poderosamente a atenação a obstinada falta de reconhecimento da consolidação que este fato fônico tem no uso contrastante da língua espanhola (MORENO FERNÁNDEZ, 2000, p. 53-54 y p. 85), porque se parte de que a variação seria objeto de ensino. Acredito, por outro lado, que questão disinta é ensiná-la e praticá-la; e outra para apresentá-la brevemente e convidar a tomar atitudes positivas quando as encontramos, como uma forma de respeito por aqueles que a apresentam, porque - em primeiro lugar - é muito mais difícil mudar a variação das comunidades falantes do que a atitude dos estudantes estrangeiros. Assim, no chamado espanhol da Andaluzia Oriental, "apesar de suas diferenças geográficas, constitui uma área compacta [...]marcado por seu caráter evolutivo. Este personagem é manifestado por um conjunto de traços entre os quais vale destacar a lenição da final silábica ${ }^{20}$...” (MOYA CORRAL, 2011, p. 104), o que reitera Manjón-Cabeza Cruz (2018, p. 148) ao apontar que "há também processos de estigmatização externa, ou seja, há fenômenos que na Andaluzia não são valorados negativamente, mas sobre os quais avaliações negativas são ponderadas por muitos usuários da variedade padrão. Este é o caso com a perda do /-s/...”.

Precisamente en Méndez García de Paredes (2008, p. 1372-1373) se desfaz, entre outros, o sentido de norma como uso reconhecido e comum da língua; ou seja, como uma prática habitual e/ou costumeira; é, portanto, "o que é", e não "o que deveria ser". Nesse sentido, temos um modelo centropeninsular que admite formas diatópicamente marcadas, “devido ao fato de que o espanhol tem um padrão relativamente flexível e permite o desbloqueio de alguns fenômenos linguísticos, estabelecendo um espanhol oral para o andaluz" (MÉNDEZ GARCÍA DE PAREDES, 2008, p. 1382). Nesse sentido, Fuentes González (1996, p. 69-74) já registrou que a chamada elisão do /-s/ era uma variante aceita na cidade de Almería. Também em um contexto andaluz mais amplo, García Marcos e ManjónCabeza Cruz (1989) revelam que para a escola primária andaluz mais jovem era desnecessário - e quase ridículo - forçar os escolares a pronunciar o /-s/, que foi, sem dúvida, um sintoma da aceitação sociolinguística desse fenômeno.

${ }^{20} \mathrm{Um}$ sinal desse enfraquecimento do/-s/ se pode ouvir se escutamos Granada Luis García Montero, professor de Literatura Espanhola na Universidade de Granada e atual diretor do Instituto Cervantes. $C f$. Disponível em: https://www.youtube.com/watch?v=iDw44nWiDvk. Acesso em: 13 nov. 2019.

Também se pode ver no granadino Motril Luis Rubiales, presidente da Real Federação Espanhola de Futebol. Disponível em: https://www.rfef.es/noticias/luis-rubiales-trabajemos-todos-supercopa-igualdad. Acesso em: 10 fev. 2020. 
Talvez seja aconselhável levar em conta um trabalho de Simone (1997, p. 30-34), onde se verificava o que ele chama de "Deformação do Linguista", que em seu cérebro estabelece que entre as formas linguísticas há uma relação de hierarquia segundo a qual a não-variação (o variandum, o ponto de fuga, a língua) é geneticamente primária, quase primitiva e representa o termo não-marcado da oposição dos códigos, de modo que o varians (a variação) gradualmente se distancia da não-variável. Para isso, certos estágios típicos, implicitamente consideradas como "degeneración", que envolvem a perda ou enfraquecimento dos traços do variandum, teoria deformadora, pois atribui antecipadamente um rótulo definitivo a cada um dos fatores com os quais enfrenta, de modo que o varians está cada vez mais estruturado e pior articulado: "Consequentemente, no final, a descrição do varians [...]inevitavelmente se apresenta descrição de um declínio, [...] de simplificação, [...] como um empobrecimento (SIMONE, 1997, p. 32).

Esses fenômenos de decadência, perda, simplificação, pronúncias rápidas e descuidadas são frequentemente atribuídos a "dialetos e variedades locais, que, por razões que não são realmente claras, parecem ontologicamente destinados ${ }^{21}$ a ser pronunciadas de maneira rápida, simplificada e intrinsecamente abaixo do padrão" (SIMONE, 1997, p. 34), precisamente o que costuma ocorrer com a perda de Almeria e Granada.

\section{Considerações finais}

Os relatos sociolinguísticos compilados das estudantes irlandesas mostram que toda atividade linguística se produz a partir de tensões e contradições. Nessa orientação, nossas alunas, opondo-se a uma realidade sociolinguística inesperada, procuraram agir, sabendo corrigir, em muitos casos, a partir do cânone anteriormente assimilado e navegando com alguma eficiência entre as dissidências vividas, atenuando seus conflitos linguísticocomunicativos a fim de orientá-las para o significado social.

Desde a língua in vitro até a língua in vivo, seus movimentos interativos dão conta de um bom dinamismo. Acredito, por conseguinte, que o enfoque autobiográfico do relato sociolinguístico pode ter grande utilidade na pesquisa, já que força a ver os alunos como como indivíduos diferentes e descobrir quais variantes e fatores influenciam o processo de aprendizagem no exterior, sem reduzi-los a receptores acríticos em um syllabus. Nesse sentido, o principal fator descoberto é seu caráter como falantes nativos do inglês, o que gera acomodação linguística através dele, em vez de em español. De fato, em outras programas, estudantes irlandesas e britânicas vieram pedir que essas disciplinas do curso de Filologia

${ }^{21}$ Destaque do autor. 
Espanhola fossem ensinadas em inglês. De certa forma, o anterior se relaciona a uma proficiência prévia limitada em espanhol, reiterada ao longo dos anos, por uma circunstância que geralmente determina um maior grau de rejeição do espanhol encontrado em Almería do que em outros grupos nacionais de estudantes erasmus. Ou seja: ser um falante nativo de inglês oferece as vantagens intrínsecas de ser monolíngue em muitos países ao redor do mundo, o que desencoraja a capacidade de esforço intercomprensivo quando começa a se tornar bilíngue.

As narrativas, como expressão da vida linguística, enfatizam que a busca experiencial e perseverante por significados se constituem um bom incentivo para a aprendizagem aprendizagem-aquisitivo linguística numa língua que, como o espanhol, é policêntrica geograficamente e situativamente, portanto Bustos Tovar (2013, p. 22) recomenda "pluricentrismo normativo versus unitarismo artificioso". Partindo desse pressuposto, o professorado deve ter extensiva formação neste respeito e transportá-la para a sala de aula (GUAJARDO, 2009; DELGADO FERNÁNDEZ, 2013), não tanto -entendo eu- para despejar (ensinar) tamanhos conteúdos em um discreto recipiente, mas como uma atitude transversal de respeito à diversidade multilíngue, também intralinguística (MAURO, 1977; FUENTES GONZÁLEZ, 1996a), sem dúvida enriquecido por padrões mais férteis de contato com falantes nativos do idioma e fatores psicossociais que a promovam (GEESLIN; GUDMESTAD, 2008).

A estrutura normativista ttem uma rota antiga e sua variação jacobina alguns séculos (FONTES GONZÁLEZ, 2017); no entanto, todos os choques linguísticos e culturais, se não eliminados, poderiam ser muito suavizados, se a partir da didática de origem contassem com essa consciência multilíngue da língua, como uma realidade múltipla, como uma experiência, e não tanto como um assunto (GONZÁLEZ PIÑEIRO; GUILLÉN DÍAZ; VEZ, 2010), que dogmatiza o conceito de língua como uma série de regras categóricas.

Santiago Guervós e Fernández González (2017, p. 209-236) acertam plenamente ao apontar a enorme densidade socio-semântica do conceit 'língua', pelo que se faz necessário apontar constantemente que a variação e a diversidade são inherentes -tanto entre as línguas como dentro delas-, o que defveria sugerir entre o profesorado de ELE, e amplamente de LE o L2, uma gestão empática das certezas y encaminhá-las mais à modestia mediante la observação que à arrogancia por formação.

Ao que se debe acrescetnar, con Casals Andreu (2005), que deveria se aproveitar o capital que representam os estudantes estrangeiros no destino para melhorar, desta forma, la competencia plurilíngue da população autóctone, inclusive em outras línguas e outras 
variedades intralinguísticas. De qualquer forma, devemos evitar uma mobilidade que gere atitudes imovíveis e continuar indagando em todas essas questões com análises mais profundas e abrangentes para chegar a conclusões mais sólidas.

\section{REFERENCIAS}

ALARCÓN, A., "Movilidad de los factores, eficiencia y discriminación lingüística: análisis de cuatro escenarios empresariales en Cataluña". Revista de Sociolingüística, n. 2, 2005. Disponible en: www.gencat.cat/llengua/noves/noves/hm05hivern/docs/alarcon.pdf. Acceso el: 30 maio 2017.

BARRAJÓN, E.; BOTELLA, P.; GIL, A. M.; KONIECZKA, K.; ORTEGA, J. M.; PASTOR, S.; PÉREZ, M. I.; PREVOST, J.; RODRÍGUEZ, A. Español académico e inmersión universitaria del alumnado extranjero en la Universidad de Alicante. In: ÁLVAREZ, J. D.; GRAU, S.; TORTOSA, M. T. (Coords.). Innovaciones metodológicas en docencia universitaria: resultados de investigación. Universitat d'Alacant, Alacant, 2016. p. 17371749.

BOLADERAS TACHÉ, J. M. L'acollida lingüística a la Universitat de Lleida. Kesse: Butlletí del Cercle d'Estudis Històrics i Socials Guillem Oliver, n. 38, p. 10-11, 2005.

BRUNER, J. La educación, puerta de la cultura. Madrid: Visor, Madrid. Vers. esp. de F. DÍAZ, [1997]1999.

CARMONA YANES, E. Propuesta de innovación docente para un análisis lingüístico activo, consciente y desautomatizado. Jornadas de Formación e Innovación Docente del Profesorado, n. 1, 2018, p. 1570-1587. Disponible en:

https://institucional.us.es/revistas/JDU/Carmona_Yanes_Elena.pdf. Acceso el: 23 dez. 2019.

CASALS ANDREU, D. L'acollida lingüística a la Universitat de Barcelona. Kesse: butlletí del Cercle d'Estudis Històrics i Socials Guillem Oliver, n. 38, p. 15-17, 2005.

COLEMAN, J. A. Cómo desarrollar percepciones interculturales entre estudiantes. In: BYRAM, M.; FLEMING, M. (Coords.). Perspectivas interculturales en el aprendizaje de idiomas. Madrid: CUP. Trad. PARRONDO; J. R. DOLAN, M. [1998]2001. p. 51-81.

DELGADO FERNÁNDEZ, R. Las variedades diatópicas como fuente de dificultades en la elección de un modelo de lengua trasladable al aula de E/LE. In: CABEDO NEBOT, A.; AGUILAR RUIZ, M. J.; LÓPEZ-NAVARRO VIDAL, E. (Coords.). Estudios de Lingüística: investigaciones, propuestas y aplicaciones. Valencia: Universidad de Valencia, 2013. p. 21-29. Disponible en:

https://www.academia.edu/7325475/Las_variedades_diat\%C3\%B3picas_como_fuente_de_dif icultades_en_la_elecci\%C3\%B3n_de_un_modelo_de_lengua_trasladable_al_aula_de_E_LE? auto=download. Acceso el: 30 jan. 2020.

BORREGO NIETO, J.; DOMÍNGUEZ GARCÍA, L.; DELGADO FERNÁNDEZ, R.; RECIO DIEGO, Á.; TOMÉ CORNEJO, C. Cocodrilos en el diccionario. Hacia dónde camina el español. Madrid: Instituto Cervantes-Espasa, 2016. 
BUSTOS TOVAR, J. J. de. Las hablas andaluzas en el mosaico de variedades del español. In: NARBONA JIMÉNEZ, A. Conciencia y valoración del habla andaluza. Sevilla: Universidad Internacional de Andalucía, Servicio de Publicaciones, 2013. p. 17-44.

FLORINDI, M. L'inglese come lingua franca nella progettazione europea: comparazione e analisi linguistica di due proposte formulate nell'ambito del programma Erasmus. 2016. Tese (Mestrado) - Università degli Studi di Modena e Reggio Emilia, Modena. Disponible en: https://morethesis.unimore.it/theses/available/etd-03192016-144456/. Acceso el: 29 jun. 2017.

\section{FUENTES GONZÁLEZ, A. D. Actitudes y conciencia sociolingüísticas en la ciudad de} Almería. Almería: GRUSTA, 1996.

FUENTES GONZÁLEZ, A. D. Enseñanza del léxico: actitudes y diversidad. In: LUQUE DURÁN, J. de D.; MANJÓN POZAS, F. J. (Coords.). Segundas jornadas sobre el estudio y la enseñanza del léxico. Granada: Método, 1996a. p. 247-252.

FUENTES GONZÁLEZ, A. D. Fluidez y metáforas del agua en novelas de la emigración española a Alemania. In: CAMPOS, M. M.; LARA RÓDENAS, M. J. de (Coords.).

Releyendo: estudios de lectura y cultura. León: Universidad de León, 2015. p. 383-396.

FUENTES GONZÁLEZ, A. D. Anarquismo, jacobinismo y Lingüística: Reflexiones sociolingüísticas acerca de la gramática del obrero (1932 [1912]), de José Sánchez Rosa. Pragmalinguiística, v. 25, p. 163-188, 2017.

FUENTES GONZÁLEZ, A. D. «Me daba vergüenza hablar en español; entonces empecé a hablar. Con errores, pero empecé»: vivencias sociolingüísticas de las estancias de ERASMUS polacos. Revista Lenguaje y textos (SEDLL, Sociedad Española de Didáctica de la Lengua y de la Literatura), 2020, en prensa.

GALINDO, M. M.; DÍEZ, F. Género y aprendizaje de idiomas. In: ROIG-VILA, R.; BLASCO, J. E.; LLEDÓ, A.; PELLÍN, N. (Coords.). Investigación e Innovación Educativa en Docencia Universitaria. Retos, Propuestas y Acciones, Universidad de Alicante, Alicante, 2016. p. 2182-2194.

GALLUCCI, S. Language learning, identities and emotions during the Year Abroad: Case studies of British ERASMUS students in Italy, 2011. Tese (Doutorado) - University of Birmingham. Disponible en: http://etheses.bham.ac.uk/1735/1/Gallucci_11_PhD.pdf. Acceso el: 21 jul. 2017.

GARCÍA MARCOS, F. J. El segmento fónico VOCAL + S en ocho poblaciones de la Costa Granadina (Aportación informática, estadística y sociolingüística al re-examen de la cuestión). EPOS, v. II, p. 155-180, 1987.

GARCÍA MARCOS, F. J. Estratificación social del español de Almería. Materiales previos y bases para su estudio. EPOS, v. IX, p. 557-569, 1993.

GARCÍA MARCOS, F. J. Fundamentos críticos de sociolingüística. Universidad de Almería, Almería, 1999. 
GARCÍA MARCOS, F.; MANJÓN-CABEZA CRUZ, A. Creencias lingüísticas en la E.G.B. Contribución a una política lingüística en Andalucía. In: CONGRESO NACIONAL DE AESLA, 5., 1989. Pamplona. Anais [...]. Pamplona: Univ. de Navarra, 1989. p. 243-249.

GARCÍA MARCOS, F. J.; FUENTES GONZÁLEZ, A. D. Cultivos lingüísticos versus etosfera lingüística. Universitat de València: Centro de Estudios sobre Comunicación Interlingüística e Intercultural, 1997.

GEESLIN, K. L.; GUDMESTAD, A. The acquisition of variation in second-language Spanish: An agenda for integrating studies of the L2 sound system. Journal of Applied Linguistics and Professional Practice, v. 5, n. 2, p. 137-157, 2008.

GEESLIN, K. L. Variation in L2 Spanish: The state of the discipline. Hispanic and Lusophone Linguistics, v. 4, n. 2, p. 461-518, 2011.

GÓNZÁLEZ PIÑEIRO, M.; GUILLÉN DÍAZ, C.; VEZ, J.M. Didáctica de las lenguas modernas. Competencia plurilingüe e intercultural. Madrid: Síntesis, 2010.

GONZÁLEZ-MONTEAGUDO, J. La entrevista biográfica como recurso: Aprendizaje e identidad en contextos universitarios internacionales e interculturales. In: MURILLO, G. J. (Comp.). Narrativas de experiencia en educación y pedagogía de la memoria. Buenos Aires: Universidad de Buenos Aires, 2015. p. 237-268.

GUAJARDO, M. G. Modèles linguistiques et variations diatopiques: attitudes et représentations des enseignants face à la pluricentricité normative en classe d'espagnol langue étrangère. 2009. Tese (Doutorado) - Université du Québec à Montréal, Montreal. Disponible en: https://archipel.uqam.ca/2616/. Acceso el: 15 jan. 2020.

IGLESIAS, M. Turismo idiomático en España. Marco teórico. International Journal of Scientific Management and Tourism, v. 4, n. 1, p. 29-59, 2018.

LAMÍQUIZ IBÁÑEZ, V. Sociolingüística en un habla urbana: Sevilla. Revista Española de Lingüística, v. 6, n. 2, p. 345-362, 1976.

LIMA, D. C. de. Formación en español con objetivos académicos: aspectos teóricos y metodológicos de la interculturalidad y la intersubjetividad en la enseñanza de lenguas. Diálogos Latinoamericanos, v. 15, n. 22, p. 46-57, 2014.

LINDQVIST, H. Marcadores metadiscursivos, fluidez y participación conversacional en español L2: La evolución de la competencia comunicativa durante la estancia en una comunidad de la lengua meta, 2017. Tese (Doutorado) - Universidad de Estocolmo, Estocolmo, 2017. Disponible en:

http://su.diva-portal.org/smash/get/diva2:1127289/FULLTEXT01.pdf. Acceso el: $01 \mathrm{dez}$. 2019.

LÓPEZ MORALES, H. Desdoblamiento fonológico de las vocales en el andaluz oriental: reexamen de la cuestión. Revista Española de Lingüística, año n. 14, Fasc. 1, p. 85-98, 1984. 
LÓPEZ SERENA, A. El andaluz y español de América en la distancia comunicativa. ¿Hacia una norma panhispánica? Itinerarios, v. 14, p. 47-73, 2011.

MANJÓN-CABEZA CRUZ, A. Creencias y actitudes de los jóvenes universitarios granadinos hacia las variedades cultas del español. Boletín de Filología, Universidad de Chile, v. 53, n. 2, p. 145-177, 2018.

MARTÍN ROJO, L.; RODRÍGUEZ, L. R. Muda lingüística y movilidad social. Trayectorias de jóvenes migrantes hacia la universidad. Discurso \& Sociedad, v. 10, n. 1, p. 100-133, 2016.

MAURO, M. T. de. Il plurilinguismo nella società e nella scuola italiana. In: SIMONE, R.; RUGGIERO, G. (Coords.). Aspetti sociolinguistici dell'Italia contemporánea. Roma: Bulzoni, 1977. p. 87-102.

MÉNDEZ GARCÍA DE PAREDES, E. Modelos idiomáticos y prescriptivismo. El caso del andaluz. In: MORENO SANDOVAL, A. (Coord.). El valor de la diversidad [meta] lingüística. CONGRESO DE LINGÜÍSTICA GENERAL, 8., 2008. Madrid. Anais [...]. Madrid: Universidad Autónoma, 2008. p. 1370-1389.

MEUNIER, D. De la «mobilité» de l'imaginaire linguistique chez les étudiants Erasmus. Synergies Pays Riverains de la Baltique, v. 7, p. 61-76, 2010.

MEUNIER, D. Mobilité et apprentissage linguistique: étude du discours métalinguistique d'apprenants Erasmus. Éla. Études de linguistique appliquée, v. 162, n. 2, p. 137-151, 2011. DOI:10.3917/ela.162.0137

MEUNIER, D. Les représentations linguistiques des étudiants Erasmus et la vision plurilingue européenne: normes, discours, apprentissages, 2013. Tesis doctoral. Université de Liège: Liège. Disponible en <https://orbi.uliege.be/handle/2268/156348> Acceso el 16 de enero de 2020.

MEUNIER, D. Apprendre les langues durant un séjour Erasmus: la compétence plurilingue entre normes et pratiques. En: NARCY-COMBES, M. F.; JOEFFRION, Ch., eds. Contributions au développement de perspectives plurilingues en éducation et formation. Des représentations aux dispositifs pour une meilleure prise en compte de la diversité, 2018, p. 51-74. Presses universitaires de Rennes.

MEURER, M. Der monolinguale Multilingualismus der EU-Sprachenpolitik. Eine Analyse der Reproduktion von Sprachideologien, 2019. Tesis (Doctoral) - University of Waterloo-Universität Mannheim, Waterloo (Canada)-Manhheim (Deutschland). Disponible en: http://hdl.handle.net/10012/15026. Acceso el: 17 jan. 2020.

MITCHELL, R.; MCMANUS, K.; TRACY-VENTURA, N. Placement type and language learning during residence abroad. In: Social interaction, identity and language learning during residence abroad, 2015. p. 115-137.

MORENO FERNÁNDEZ, F. ¿Qué español enseñar? Madrid: Arco/Libros, 2000. 
MOYA CORRAL, J. A. El oriente andaluz y el español común. In: MOYA CORRAL, J. A.; SOSINSKI, M. (Coords.). Estudios Sobre la Lengua Española y su Enseñanza. Granada: Universidad de Granada, 2011. p. 101-116.

PÉREZ VIDAL, C. Les Estades a l'estranger i l'adquisició de la llengua i la cultura. Llengua, societat i comunicació, n. 5, p. 20-26, 2007.

PINAR, A. La influencia de las estancias en el extranjero en el proceso de aprendizaje de segundas lenguas. 2015. Tesis (Doctoral) - Universitat de Barcelona, Barcelona, 2015. Disponible en: http://www.tdx.cat/handle/10803/286631. Acceso el: 23 dez. 2019.

POZO-VICENTE, C.; AGUADED-GÓMEZ, J. I. "El programa de movilidad ERASMUS: motor de la adquisición de competencias interculturales". Revista de Investigación Educativa, v. 30, n. 2, p. 441-458, 2012.

RECAJ, F. Factores que influyen en el acento extranjero: estudio aplicado a aprendices estadounidenses de español. 2008. Tesis (Doctoral) - Universidad de Salamanca, Salamanca, 2008 .

RINGER-HILFINGER, K. Learner acquisition of dialect variation in a study abroad context: The case of the Spanish [0]. Foreign Language Annals, v. 45, n. 3, p. 430-446, 2012.

SALGADO-ROBLES, F. The acquisition of sociolinguistic variation by learners of Spanish in a study abroad context. 2011. Tesis (Doctoral) - University of Florida, 2011. Disponible en: https://search.proquest.com/docview/922269181?pq-origsite=gscholar. Acceso el: 17 jan. 2020.

SANTIAGO GUERVÓS, J. de; FERNÁNDEZ GONZÁLEZ, J. Fundamentos para la enseñanza del español como 2/L. Madrid: Arco/Libros-La Muralla, 2017. 936p.

SALVADOR, G. Unidades fonológicas vocálicas en andaluz oriental. Revista de la Sociedad Española de Lingüística, año n. 7, fasc. 1, p. 1-23, 1977.

SIMONE, R. ¿Cuál es la lengua de default en un ambiente de variación? En: NARBONA, A.; ROPERO, M. (Coords.). In: CONGRESO DEL HABLA ANDALUZA, 1997. Sevilla. Anais [...]. Sevilla: Universidad de Sevilla, 4-7 mar. 1997. p. 29-41.

VÁZQUEZ, G. "Un análisis didáctico del discurso académico español como contribución a la movilidad estudiantil europea". In: ESCOFET, A.; JONGE, B. de; HOOFT, A.van; JAUREGI, K.; ROBISCO, J.; RUIZ, M. (Coords.). CONGRESO INTERNACIONAL DE ESPAÑOL PARA FINES ESPECÍFICOS UTRECHT, 3., 2006. Utrecht. Anais [...]. Utrecht: Consejería de Educación en Países Bajos, Bélgica y Luxemburgo/Embajada de España, nov. 2006. p. 133-144. Disponible en:

https://www.researchgate.net/profile/Andreu_Van_hooft2/publication/236852093_Espanol_p ara_Fines_Especificos_Actas_del_III_Congreso_Internacional_de_Espanol_para_Fines_Espe cificos_Utrecht_noviembre_de_2006/links/0046351969dc10608e000000.pdf\#page=133. Acceso el: 26 de abr. de 2020. 
Como referenciar este artigo.

FUENTES GONZÁLEZ, Antonio Daniel. A realidade e o padrão nas estadias de estudantes irlandeses de ERASMUS: "No entendí nada. Ahora, estoy acostumbrado a esta desesperación de LA «S»". Rev. EntreLínguas, Araraquara, v. 6, n. 1, p. 123-145, jan./jun., 2020. e-ISSN: 2447-3529. DOI: https://doi.org/10.29051/el.v5i1.12599

Submetido em: 30/07/2019

Revisões requeridas em: 30/08/2019

Aceito em: 30/11/2019

Publicado em: 06/01/2020 